\title{
Enquête
}

Archives de la revue Enquête

$7 \mid 1992$

Max Weber

\section{Note sur les traductions}

Jean-Pierre Grossein

\section{OpenEdition}

\section{Journals}

Édition électronique

URL : http://journals.openedition.org/enquete/127

DOI : 10.4000/enquete. 127

ISSN : 1953-809X

\section{Éditeur :}

Cercom, Éditions Parenthèses

\section{Édition imprimée}

Date de publication : 2 juin 1992

\section{Référence électronique}

Jean-Pierre Grossein, « Note sur les traductions », Enquête [En ligne], 7 | 1992, mis en ligne le 12 janvier 2006, consulté le 23 avril 2019. URL : http://journals.openedition.org/enquete/127 ; DOI : 10.4000/ enquete. 127

Ce document a été généré automatiquement le 23 avril 2019. 


\title{
Note sur les traductions
}

\author{
Jean-Pierre Grossein
}

1 Il n'est pas utile de se lamenter sur la difficulté à traduire Weber : la cause est entendue ; en revanche on est en droit de se plaindre de la qualité de certaines traductions qui nuisent doublement à la connaissance de l'œuvre wébérienne : d'abord par le fait même de leurs déficiences, mais également parce qu'en existant elles découragent les éditeurs et les traducteurs d'en présenter une nouvelle version.

2 C'est ce que nous avons pourtant tenté avec le premier texte ici présenté (l'«Introduction») dont une première traduction avait été publiée dans les Archives de Sciences sociales des Religions, 9 (1960), amputée de toute la dernière partie relative à la typologie de la domination.

3 Le deuxième texte ( Confucianisme et puritanisme ») n'a toujours pas fait l'objet d'une traduction; il s'agit du chapitre de conclusion de l'étude Confucianisme et Taoïsme; son titre exact est : « VIII. Résultat : confucianisme et puritanisme ».

4 Pour les deux premiers textes, nous nous sommes servi de l'édition critique, puisqu'ils sont tous deux contenus dans le tome I-19; nous avons indiqué les variantes entre la $1^{\text {re }}$ édition (1915) et la $2^{\mathrm{e}}$ édition (1920) uniquement quand elles nous semblaient proposer des précisions importantes ou témoigner d'infléchissements éventuels de l'analyse. Les ajouts lors de l'édition de 1920 sont signalés par des crochets. Nous avons conservé la graphie adoptée par Weber pour les noms chinois.

5 La traduction du troisième texte était déjà réalisée au moment de la publication de l' Histoire économique. Esquisse d'une histoire universelle de l'économie et de la société (Gallimard, 1991, traduction par C. Bouchindhomme). Sa publication ici est destinée à étayer l'argumentation de la présentation ; elle ne prétend à aucune supériorité par rapport à la susmentionnée. Nous devons seulement rappeler - ce qu'omet de faire l'éditeur de l' Histoire économique - qu'il ne s'agit pas strictement d'un texte de Weber, mais de notes prises à partir des derniers cours tenus par Weber pendant le semestre 1919-1920 et publiées en 1923. La traduction ci-dessous est celle du dernier chapitre de l'ouvrage. 
6 Chacun verra que nous avons pris le parti de la littéralité au risque de la lourdeur, soutenus dans cette démarche par J.-C. Passeron, à qui nous tenons à exprimer toute notre gratitude pour les critiques et suggestions qu'il nous a faites lors de la lecture ultime et minutieuse de ce texte à laquelle il a procédé ; je ne saurais oublier J.-P. Briand qui m'a fait l'amitié de relire attentivement une première fois ces traductions ; enfin, j'ai tiré grand profit, également, des remarques stylistiques proposées par J.-L. Schlegel. 